\title{
Hard and soft electrophilic and nucleophilic dissymmetry of $\alpha$-oxoketenedithioacetals and $p$-nitro-o-phenylenediamine exploited to achieve the regioselectivity in the synthesis of 2-thiomethyl ether substituted isomer of the privileged nucleus of 1,5-benzodiazepines over to its 4-substituted isomers
}

\author{
PRIYANKA CHAUDHARY*, AARTI GUPTA, PRAGATI DEVI and DHARMA KISHORE \\ Department of Chemistry, Banasthali University, Banasthali, 304 022, India \\ e-mail: priyankachaudhary2009@gmail.com
}

MS received 4 February 2012; revised 30 July 2012; accepted 30 August 2012

\begin{abstract}
An exclusive regioselective formation of 2-thiomethyl ether substituted isomer of the privileged nucleus of 1,5-benzodiazepines was achieved from the reaction of $p$-nitro- $o$-phenylenediamine with a variety of $\alpha$-oxoketene dithioacetals derived from several active methylene compounds, by exploiting the strategy based on the variation of electrophilicity of the two electrophilic centers of $\alpha$-oxoketene dithioacetals and the hard and soft nucleophilic profiles of the $p$-nitro substituted $o$-phenylenediamines.
\end{abstract}

Keywords. Regioselectivity in synthesis; 1,5 -benzodiazepines; $\alpha$-oxoketene dithioacetals; hard and soft dissymmetry of electrophilic and nucleophilic species.

\section{Introduction}

Impressive biological properties displayed by privileged nucleus of 1, 5-benzodiazepines have triggered the development of a variety of methods for their synthesis. ${ }^{1}$ The factors based on the reactivity and easy availability of starting materials together with the simplicity in the operational procedures have led the reaction of $o$-phenylenediamine with $\beta$-dicarbonyl compounds, ${ }^{2} \beta$-ketoesters, ${ }^{3} \alpha, \beta$-unsaturated ketones ${ }^{4}$ and $\beta$-haloketones ${ }^{5}$ to emerge as a most versatile method for the synthesis of 1,5-benzodiazepines. But the utilization of many of these processes in synthesis from unsymmetrically substituted $o$-phenylenediamines suffers from a serious drawback of giving a mixture of two isomer ( 2 and 4 substituted derivatives) of 1,5benzodiazepines. In such cases the position of the substituent in the seven-membered ring with respect to substituent in arene ring remains unpredictable since the carbonyl species has equal opportunity to react at the alternate site of the diamine component to yield a mixture of two regioisomers, whose separation and characterization proves to be a cumbersome process. Owing to this reason, these processes have a limited scope and application in synthesis, when the formation

*For correspondence of only one regio-isomer is desired. For our work, we required a good synthesis of 2-thiomethyl ether substituted derivative of 1, 5-benzodiazepines for its subsequent conversion to its 2-substituted analogues and for the preparation of face ' $a$ ' annulated analogues of this molecule. From the structure of 1,5-benzodiazepine2-one, it was apparent that $\mathrm{C}_{2}$ carbonyl function of this nucleus containing the $\mathrm{NH}-\mathrm{C}=\mathrm{O}$ group is the only site in the seven-membered ring which provides scope for its further structural manipulations to form the 2-substituted derivatives of medicinal utility. Though $\mathrm{NH}-\mathrm{C}=\mathrm{O}$ group has the potential to provide an easy access to the corresponding lactim thioether function through its reaction with $\mathrm{P}_{2} \mathrm{~S}_{5}$ (or Lawesson's reagent) followed by treatment with $\mathrm{CH}_{3} \mathrm{I}$ but its formation required two additional steps from the amide. We were interested in a synthesis which not only provided a single regioisomer from the unsymmetrically substituted diamine substrate, but at the same time it also installed an S-Me group at 2-position of 1, 5-benzodiazepine nucleus for its subsequent use in our work.

In a quest of exploring the formation of one regioisomer from unsymmetrically substituted $O$ phenylenediamines, we revisited on the reaction of 4-nitro- $o$-phenylenediamine with the $\alpha$-oxoketene dithioacetal derivative of acetophenone with an aim to examine the role of electron withdrawing substituent present in the amine component, on this reaction. We 


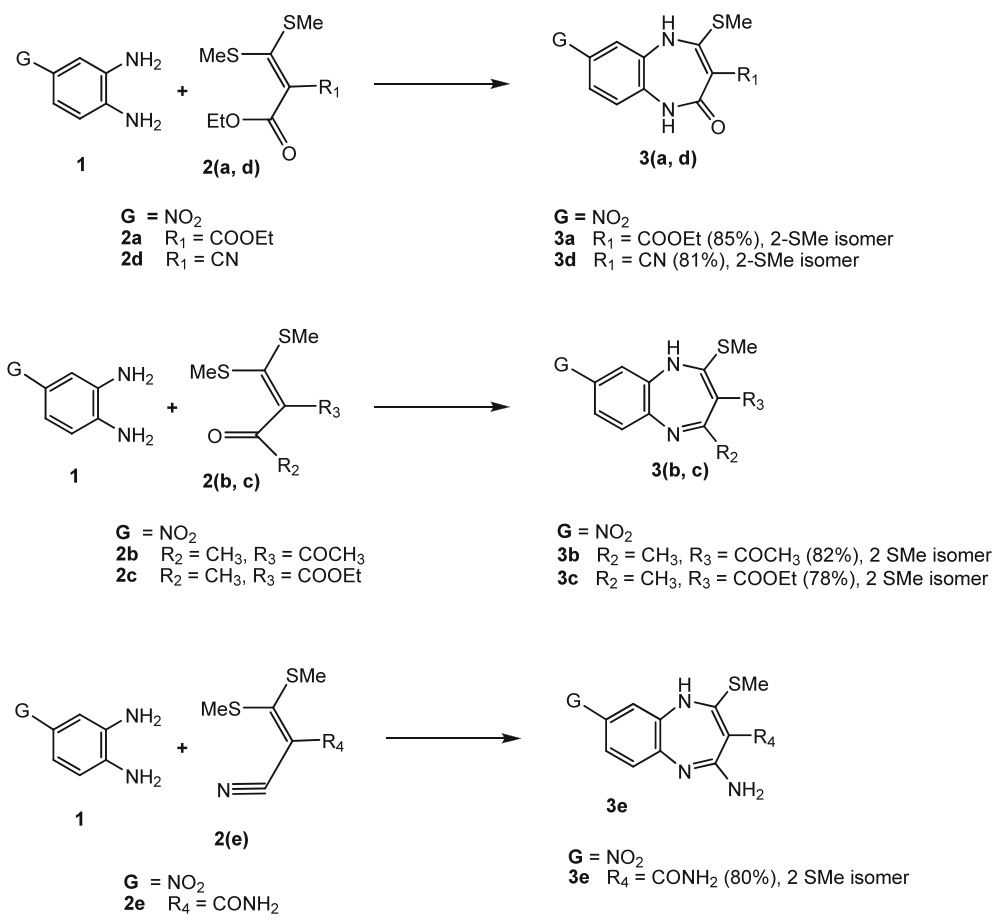

Scheme 1. Synthesis of 2-Sme substituted isomers.

observed that the amine function with a para nitro group preferred to exclusively react to the carbonyl function of the $\alpha$-oxoketene dithioacetals, leaving behind the other amine function to participate in the nucleophilic displacement of the vinylic thio ether function (of the dithioacetal group) to produce one regioisomer exclusively, in good yield. The result indicated that it was the effect of para placed electron withdrawing nitro group which exercised a strict control on the regioselctivity in this reaction. We believe that this observed regioselectivity is to be rationalized in terms of the $\alpha$-oxoketene dithioacetals having two electrophilic centres which differed in their electrophilicity and displayed, hard and soft dissymmetry. ${ }^{6}$ The presence of the bis thiomethyl groups rendered the $\beta$-carbon atom (with respect to the carbonyl function) into a soft electrophilic centre allowing only the hard nucleophiles to participate in reaction on this site, while a hard electrophilic character of the oxocarbon atom permitted only the soft nucleophile to interact at this centre in the reaction. It can be generalized from this, that in reactions with $\alpha$-oxoketene dithioacetals the regioselectivity depended on the hard and soft profiles of the bidentate nucleophilic diamine species.

Encouraged by the potential shown by $\alpha$-oxoketene dithioacetal derivative of acetophenone in facilitating the regioselective formation of one isomer from the unsymmetrically substituted bidentate arylamine substrate, ${ }^{7}$ we considered that it is of interest to examine the general applicability and versatility of this technique on other $\alpha$-oxoketene dithioacetals derived from a wide variety of active methylene substrates such as diethyl malonate, acetyl acetone, ethyl acetoacetate, ethyl cyanoacetate, cyanoacetamide, etc. in providing a regioselective formation of one isomer only, from aryldiamine species. In this communication, we present the preliminary results of our study directed toward exploiting the inherent potential of these exceedingly useful electrophilic synthons in providing an easy access to one regioisomer of 1, 5-benzodiazepines (scheme 1).

Note: Though mechanistically the 4-SMe isomer (A and $\mathrm{C}$ ) and corresponding imidazoline derivative $\mathrm{B}$ and D could also result from these reactions, but as these were formed in trace amounts, they could not be isolated in pure form from the mixture to prove their existence.

\section{Experimental}

\subsection{General}

Melting points were determined in open glass capillary and are uncorrected. Progress of reaction was monitored by using TLC on silica gel ' $G$ ' coated plates using benzene: methanol (9:1). IR spectra on $\mathrm{KBr}$ were recorded on FTIR-8400S, CE (SHIMADZU). Mass spectra were taken on $3000 \mathrm{LC} / \mathrm{MS}$ system. ${ }^{1} \mathrm{HNMR}$ spectra were recorded on model AC-300 F (Brucker) using $\mathrm{CDCl}_{3} / \mathrm{DMSO}-\mathrm{d}_{6}$ as solvent. Chemical shift $(\delta)$ 
are given in ppm relative to signal for TMS as internal standard.

\subsection{General method for preparation of ethyl-2, 5-dihydro-2-(methylthio)-7-nitro-4-oxo-1,5- benzodiazepine-3-carboxylate \\ $3(a-e)$}

A mixture of 4-nitro- $o$-phenylenediamine $(1.53 \mathrm{~g}$, $0.01 \mathrm{M}$ ) and diethyl-2 (bis(methylthio)methylene malonate $(0.528 \mathrm{~g}, 0.002 \mathrm{M})$ in DMF $(25-30 \mathrm{ml})$ was refluxed for $1.5 \mathrm{~h}$ at $150^{\circ} \mathrm{C}$. The solvent was then distilled under reduced pressure and the residue was quenched in crushed ice. It was then extracted with chloroform, washed with water and dried over anhy.sodium sulphate and finally purified on silica gel column by eluting through the solvent system (benzene and methanol, 10:2) to give the product 3a. Other compounds $3 \mathbf{b}-\mathbf{e}$ were prepared using the same procedure.

2.2a (3a): $1 \mathrm{gm}$, Yield (80\%) m.p $185-86^{\circ} \mathrm{C}$; IR $\left(\mathrm{cm}^{-1}\right): 3210(\mathrm{NH}), 2910(\mathrm{C}-\mathrm{H}$ str $\mathrm{ArH}), 1560(\mathrm{C}=\mathrm{Cstr}$ ArH $), 1700(\mathrm{C}=\mathrm{O}(\mathrm{CONH}), 1620(\mathrm{C}=\mathrm{O}), 680$ (C-S str), 1500, $1330\left(\mathrm{NO}_{2}\right) ;{ }^{1} \mathrm{H} \mathrm{NMR}(\delta): 4.0(1 \mathrm{H}, \mathrm{s}, \mathrm{Ar} \mathrm{C}-\mathrm{NH})$, $8.0\left(1 \mathrm{H}, \mathrm{s}, \mathrm{sec}\right.$.amide), $2.25\left(3 \mathrm{H}, \mathrm{s}, \mathrm{CH}_{3}\right.$ of $\left.\mathrm{SMe}\right), 1.30$ (3H,s,methyl), 4.19 (2H,s,methylene), 7.37 (1H,s, Ar $\mathrm{CH}), 7.65$ (1H,d,Ar CH), 7.53 (1H,d,Ar CH); MS:m/z $323.22\left(\mathrm{M}^{+} 85 \%\right), 251.03$ (65\%), 278 (100\%); Calcd (\%) for $\mathrm{C}_{13} \mathrm{H}_{13} \mathrm{~N}_{3} \mathrm{O}_{5} \mathrm{~S}$ : C; 48.29, $\mathrm{H}$; 4.05, N; 13.00, S; 9.72 Found: C; 48.38, H; 4.10, N; 13.17, S; 9.92.

2.2b (3b): 0.987 gm, Yield (75\%) m.p 165-66 ${ }^{\circ} \mathrm{C}$; IR $\left(\mathrm{cm}^{-1}\right): 3280(\mathrm{NH}), 2960(\mathrm{C}-\mathrm{H}$ str $\mathrm{Ar}-\mathrm{H}), 1530(\mathrm{C}=\mathrm{C}$ str $\mathrm{Ar}-\mathrm{H}), 1680(\mathrm{C}=\mathrm{O}), 650(\mathrm{C}-\mathrm{S}), 1510,1310\left(\mathrm{NO}_{2}\right)$ $1627(\mathrm{C}=\mathrm{N}) ;{ }^{1} \mathrm{H} \mathrm{NMR}(\delta): 4.0(1 \mathrm{H}, \mathrm{s}, \mathrm{Ar} \mathrm{C}-\mathrm{NH}), 0.9$ $\left(3 \mathrm{H}, \mathrm{s}, \mathrm{CH}_{3}\right), 2.25\left(3 \mathrm{H}, \mathrm{s}\right.$, methyl), $2.30\left(3 \mathrm{H}, \mathrm{s}, \mathrm{CH}_{3}\right), 7.4$ $(1 \mathrm{H}, \mathrm{s}, \mathrm{Ar} \mathrm{CH}), 7.6(1 \mathrm{H}, \mathrm{d}, \mathrm{Ar} \mathrm{CH}), 7.3(1 \mathrm{H}, \mathrm{d}, \mathrm{Ar} \mathrm{CH})$; MS:m/z 291 (M+ 80\%), 229.53 (85\%), 276.13 (100\%); Calcd (\%) for $\mathrm{C}_{13} \mathrm{H}_{13} \mathrm{~N}_{3} \mathrm{O}_{3} \mathrm{~S}: \mathrm{C} ; 53.60, \mathrm{H} ; 4.50, \mathrm{~N}$; 14.42, S; 11.01 Found: C; 53.74, H; 4.55, N; 14.54, S; 11.16 .

2.2c (3c): 1 gm, Yield (80\%) m.p 200-202 ${ }^{\circ} \mathrm{C}$; IR $\left(\mathrm{cm}^{-1}\right): 3410(\mathrm{NH}), 3000(\mathrm{C}-\mathrm{H}$ str $\mathrm{ArH}), 1580(\mathrm{C}=\mathrm{C})$, $1710(\mathrm{C}=\mathrm{O}), 650(\mathrm{C}-\mathrm{S}), 1535,1300\left(\mathrm{NO}_{2}\right), 1627$ $(\mathrm{C}=\mathrm{N}) ;{ }^{1} \mathrm{H}$ NMR $(\delta): 4.0(1 \mathrm{H}, \mathrm{s}$ Ar CH$), 2.25\left(3 \mathrm{H}, \mathrm{s}, \mathrm{CH}_{3}\right.$ of SMe), 1.30 (3H,s,methyl), 4.19 (2H,s,methylene), $0.9\left(3 \mathrm{H}, \mathrm{s}, \mathrm{CH}_{3}\right), 7.4(1 \mathrm{H}, \mathrm{s}, \mathrm{Ar} \mathrm{CH}), 7.6(1 \mathrm{H}, \mathrm{d}, \mathrm{Ar} \mathrm{CH})$, 7.3 (1H,d,Ar CH); MS:m/z $321.05\left(\mathrm{M}^{+} 75 \%\right), 277.43$ (55\%), 292.15 (100\%); Calcd (\%) for $\mathrm{C}_{12} \mathrm{H}_{11} \mathrm{~N}_{3} \mathrm{O}_{4} \mathrm{~S}$ : C; 49.14, H; 3.78, N; 14.33, S; 10.63 Found: C; 49.20, H; $3.80, \mathrm{~N} ; 14.45, \mathrm{~S} ; 10.88$. 2.2d (3d): 1 gm,Yield (80\%) m.p 206-208 ${ }^{\circ} \mathrm{C}$; IR $\left(\mathrm{cm}^{-1}\right): 3300(\mathrm{NH}), 2920(\mathrm{C}-\mathrm{H}$ str ArH $), 1538(\mathrm{C}=\mathrm{C})$, $1700(\mathrm{C}=\mathrm{O}), 1335(\mathrm{CN})$ 1568, $1340 \quad\left(\mathrm{NO}_{2}\right) ;{ }^{1} \mathrm{H}$ $\operatorname{NMR}(\delta): 4.0(1 \mathrm{H}, \mathrm{s}$ Ar CH), 8.0 (1H,s,sec.amide), $2.25\left(3 \mathrm{H}, \mathrm{s}, \mathrm{CH}_{3}\right.$ of $\left.\mathrm{SMe}\right), 7.37(1 \mathrm{H}, \mathrm{s}, \mathrm{Ar} \mathrm{CH}), 7.65$ (1H,d,Ar CH), 7.53 (1H,d,Ar CH); MS:m/z $276.11\left(\mathrm{M}^{+}\right.$ $80 \%), 203.31$ (65\%), 250.12 (100\%); Calcd (\%) for $\mathrm{C}_{11} \mathrm{H}_{8} \mathrm{~N}_{4} \mathrm{O}_{3} \mathrm{~S}: \mathrm{C} ; 47.82, \mathrm{H} ; 2.82, \mathrm{~N} ; 20.28, \mathrm{~S} ; 11.61$ Found: C; 47.90, H; 2.85, N; 20.28, S; 11.72 .

2.2e (3e): $0.876 \mathrm{gm}$, (Yield 70\%) m.p 182-83 ${ }^{\circ} \mathrm{C}$; IR $\left(\mathrm{cm}^{-1}\right): 3360(\mathrm{NH}), 2915(\mathrm{C}-\mathrm{H}$ str $\mathrm{ArH}), 1590$ $(\mathrm{C}=\mathrm{C}), 1610(\mathrm{C}=\mathrm{O}), 3310\left(\mathrm{NH}_{2}\right), 1630(\mathrm{C}=\mathrm{N}), 660$ $(\mathrm{C}-\mathrm{S}), 1600,1310\left(\mathrm{NO}_{2}\right) ;{ }^{1} \mathrm{H} \mathrm{NMR}(\delta): 4.0(1 \mathrm{H}, \mathrm{s} \mathrm{Ar}$ $\mathrm{CH}), 2.25$ (3H,s, $\mathrm{CH}_{3}$ of SMe), 2.0 (2H,s,amine), 6.0 (2H,s,pri.amide), 7.4 (1H,s, Ar CH), $7.6(1 \mathrm{H}, \mathrm{d}, \mathrm{Ar} \mathrm{CH})$, 7.3 (1H,d,Ar CH); MS:m/z $293.30\left(\mathrm{M}^{+} 70 \%\right), 261.28$ (40\%), 277.33 (100\%); Calcd (\%) for $\mathrm{C}_{11} \mathrm{H}_{11} \mathrm{~N}_{4} \mathrm{O}_{3} \mathrm{~S}$ : C; 45.04, H; 3.78; N; 23.88; S; 10.83 Found: C; 45.15, H; 3.82, N; 23.95, S; 10.91 M.P 182-83.

\section{Results and discussion}

In view of the tremendous potential of $\alpha$-oxoketene dithioacetals in synthesis, a large number of active methylene compounds have been converted into corresponding $\alpha$-oxoketene dithioacetals with many permutation and combination of the substituents. ${ }^{7}$ The presence of the carbonyl functionality and its position in conjugation with double bond carrying the bis-alkyl thio group at the $\beta$-position of carbonyl function has placed them among the most versatile 1,3-electrophilic, 3 -carbon equivalents for their reaction with bidentate nucleophiles to offer an unprecedented opportunity to a chemist for the construction of a variety of carbocyclic, alicyclic and heterocyclic rings. ${ }^{8} \alpha$-Oxoketene dithioacetals $2(\mathbf{a}-\mathbf{e})$ were readily obtained ${ }^{9}$ from the corresponding active methylene compounds on their reaction with $\mathrm{CS}_{2}$ in the presence of a base (NaOEt) followed by alkylation with methyl iodide, in a one pot reaction.

A perusal of literature on the reaction of $\alpha$-oxoketene dithioacetals derived from active methylene compounds and $o$-phenylenediamine revealed that the potential of this process to the synthesis of 1, 5-benzodiazepines has been less utilized than other methods. One reason for the lack of interest in this process was perhaps that a simple reaction of $\alpha$-oxoketene dithioacetals with an electron releasing unsymmetrically substituted $o$-phenylenediamine invariably resulted the formation of two regioisomers in unequal amounts. It proved to be difficult to obtain any one of these in the pure 


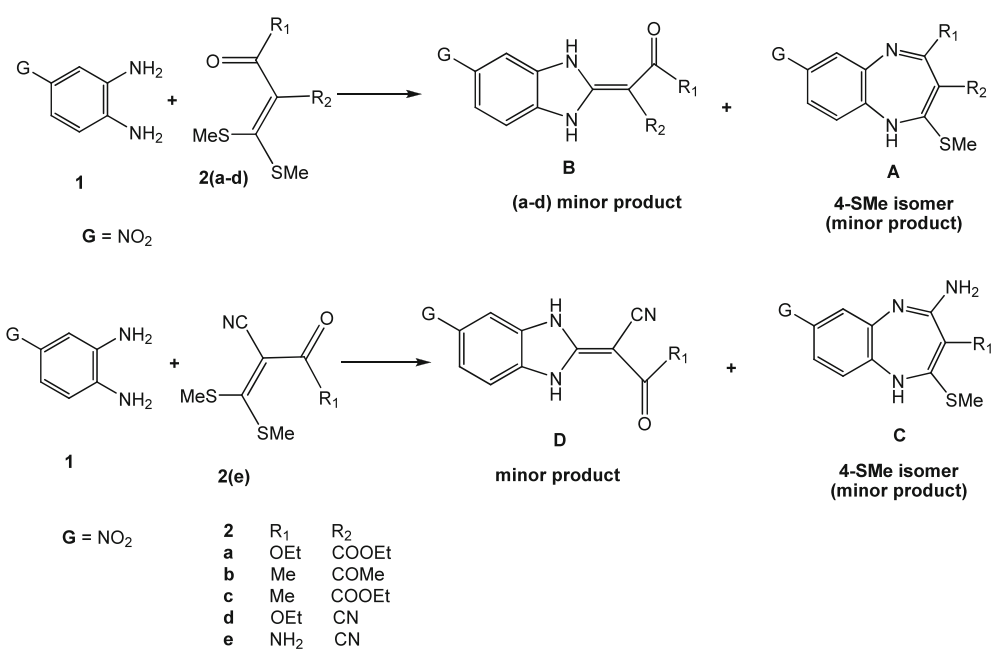

Scheme 2. Synthesis of 4-Sme substituted isomers.

form, in an acceptable yield from the mixture. We required for our work, the regioisomer which contained the thiomethyl ether group at 2-position in 1, 5benzodiazepine nucleus for its further elaboration using established procedures. This process proved to be inadequate to the preparation of 2-SMe substituted regioisomer, since it yielded the corresponding 4-SMe isomer as well. This caused the chemistry and biological evaluation of the 1,5-benzodiazepines derived from $o$-phenylendiamines and $\alpha$-oxoketene dithioacetals to remain held back and not to be exploited much in the literature. In this communication, we report the preliminary results of our endeavor directed in precluding the formation of the 4-SMe substituted regioisomer in the above reaction. Our efforts have allowed to circumvent the formation of the undesirable 4-SMe isomer in the reaction of the aryldiamines containing an electron withdrawing substitutent (such as the nitro group) at its para position in the reaction with a variety of $\alpha$-oxoketene dithioacetals and resulted exclusive formation of 2-thiomethyl ether derivatives.

We believe that in these reactions the controlling factor on regioselectivity, was the variation in the nucleophilicity of the two amine functions of the diamine component. The reaction initially proceeded through the displacement of one of the vinylic thioether function of $\alpha$-oxoketene dithioacetals $\mathbf{6}(\mathbf{a}-\mathbf{e})$ by the more nucleophilic amine function. The weak nucleophilic character of the other amine containing the nitro group at its para position, precluded its reaction on this site. The only other available site where this weak electrophilic amine could react was the carbonyl function of the $\alpha$-oxoketene dithioacetals 2 (a-e). This directional setting in reaction resulted in the exclusive formation of only one isomer- the 2-thiomethyl substituted derivative of 1, 5-benzodiazepines $\mathbf{3}(\mathbf{a}-\mathbf{e})$, respectively.
Incidentally, it was this isomer, which we had required for our purpose in exploring its potential, to the synthesis of face 'a' annulated 1, 5-benzodiazepine analogues of medicinal utility. However, the possibility of the formation of A, B, $\mathbf{C}$ and $\mathbf{D}$ (scheme 2) could not be ruled out, but as these compounds were formed only in traces, these could not be isolated in the pure form, to prove their existence.

\section{Conclusions}

In summary, we have established the regioselective formation of 2-thiomethyl ether derivative of 1,5benzodiazepines over to its 4-thiomethyl ether isomer in the reaction of oxoketenedithioacetals (derived from active methylene compounds) and $p$-nitro- $o$ phenylenediamine. Its formation was rationalized in terms of the hard and soft electrophilic and nucleophilic dissymmetry of the reacting species.

\section{Acknowledgements}

Authors are thankful to the Punjab University, Chandigarh for providing the spectral data of the compounds.

\section{References}

1. Chadha S, Paul S and Kapoor K K 2011 J. Chem. Pharm. Res. 3(2) 331

2. Wang Z X and Qin H L 2005 J. Hetrocycl. Chem. 42(5) 1001

3. Weil X L, Min Z and Hua S W 2011 Chem. Res. Chinese Universities 27228

4. Kuo C W, Wang C C, Kavala V and Yao C F 2008 Molecules 13(9) 2313

5. (a) Kumar R and Joshi Y C 2007 Arkivoc 13 142; (b) Kumar R and Joshi Y C 2008 J. Serb. Chem. Soc. 73(10) 
937; (c) Parveen A, Patil V A, Baseer M A and Ahmed S K 2011 Int. J. Ind. Chem. 2(3) 144

6. Yadav K M, Mohanta P K, lla H and Junjappa H 1996 Tetrahedron $\mathbf{5 2} 14049$

7. Junjappa H, Ila H and Asokan C V 1990 Tetrahedron 46(16) 5423
8. Mang W, Shao-Gaung S and Qun L 2004 Synth. Commun. 34(2) 287

9. (a) Ali S M and Tanimoto S 1990 Bull. Inst. Chem. Res. 68(3) 199; (b) Marino J P and Kostusyk J L 1979 Tetrahedron Lett. 20(27) 2489; (c) Chauhan S M S and Junjappa H 1976 Tetrahedron 32(14) 1779 